\title{
The optimal oral dose selection of ibandronate in Japanese patients with osteoporosis based on pharmacokinetic and pharmacodynamic properties
}

\author{
Kiyohiko Nakai • Masato Tobinai · Junko Hashimoto • \\ Satofumi Iida · Takehiko Kawanishi
}

Received: 26 August 2014/ Accepted: 22 November 2014/Published online: 5 December 2014

(C) The Author(s) 2014. This article is published with open access at Springerlink.com

\begin{abstract}
Ibandronate is a drug widely used outside Japan for the treatment of osteoporosis. It is available in formulations for intermittent intravenous (i.v.) administration and for intermittent (once monthly) oral administration. Ibandronate was recently approved in Japan as an i.v. injection with a dosing regimen of $1.0 \mathrm{mg}$ once a month. To establish the optimal dose for oral administration of ibandronate in Japanese osteoporotic patients, we investigated the pharmacokinetics of and pharmacodynamic response to ibandronate following oral and intravenous administrations to Japanese subjects. Ibandronate $(20,50,100$, or $150 \mathrm{mg})$ was given orally to healthy postmenopausal Japanese women and to Japanese patients with primary osteoporosis. Serial measurements were obtained for the concentrations of serum ibandronate and urinary cross-linked C-telopeptide of Type I collagen (uCTX). Pharmacokinetic parameters and the time profiles of creatinine-corrected UCTX were compared with those obtained from postmenopausal Japanese women with osteopenia after administration of $1.0 \mathrm{mg}$ i.v. ibandronate. Following oral administration of ibandronate, the area under the serum ibandronate concentration-time curve $\left(\mathrm{AUC}_{\mathrm{inf}}\right)$ increased dose-proportionally for doses up to
\end{abstract}

Electronic supplementary material The online version of this article (doi:10.1007/s13318-014-0242-5) contains supplementary material, which is available to authorized users.

K. Nakai $(\bowtie) \cdot$ M. Tobinai · S. Iida · T. Kawanishi Clinical Research Planning Department, Chugai Pharmaceutical Co., Ltd., 2-1-1, Nihonbashi Muromachi, Chuo-ku,

Tokyo 103-8324, Japan

e-mail: nakaikyh@chugai-pharm.co.jp

J. Hashimoto

Primary Life Cycle Management Department,

Chugai Pharmaceutical Co., Ltd., Tokyo, Japan
$100 \mathrm{mg}$; at $150 \mathrm{mg}, \mathrm{AUC}_{\mathrm{inf}}$ increased beyond the doseproportionality seen with doses up to $100 \mathrm{mg}$. The $\mathrm{AUC}_{\mathrm{inf}}$ within the linear range following administration of $100 \mathrm{mg}$ oral ibandronate was similar to that following $1.0 \mathrm{mg}$ i.v. ibandronate. Additionally, corrected uCTX decreased after administration of $100 \mathrm{mg}$ oral ibandronate and remained decreased for 1 month; the magnitude of the decrease was similar to or greater than that obtained after $1.0 \mathrm{mg}$ i.v. ibandronate. From a clinical pharmacological perspective, administration of $100 \mathrm{mg} /$ month oral ibandronate was equivalent to that of $1.0 \mathrm{mg} / \mathrm{month}$ i.v. ibandronate.

Keywords Ibandronate - Japanese - Pharmacokinetics . Pharmacodynamics

\section{Introduction}

Ibandronate is a nitrogen-containing bisphosphonate that inhibits bone resorption. It is used worldwide as an osteoporosis treatment that can be administered at extended between-dose intervals. It is available in formulations for both i.v. and oral administration. The efficacy of ibandronate is reported to be equivalent to or more potent than that of alendronate or risedronate (Dunford et al. 2001). In Japan, ibandronate is currently the only bisphosphonate approved for once-monthly bolus i.v. administration. It has been on the market in Japan since 2013, and an oral formulation for the Japanese market is currently under development. The approved dose of i.v. ibandronate in Japan is $1.0 \mathrm{mg}$ once a month, and its non-inferiority with respect to $2.5 \mathrm{mg}$ once-daily oral risedronate was demonstrated in the MOVER study, in which the endpoint was the fracture risk reduction rate (Nakamura et al. 2013). 
After oral administration, the drug is generally absorbed from the gastrointestinal tract and enters the bloodstream, and the drug subsequently produces its effect after reaching the target site. If the pharmacokinetics (PK), which characterizes the behavior of the drug in the body, and the pharmacodynamic (PD) response to the drug, which is an indicator of its effect, are same between oral and i.v. administration, it can be concluded that both routes of administration are equally effective.

Clinical studies of oral ibandronate conducted to date, mainly in Caucasian populations, have revealed the following PK and PD characteristics (Barrett et al. 2004). The time to maximum serum concentration $\left(T_{\max }\right)$ is $<1 \mathrm{~h}$, demonstrating rapid absorption; oral bioavailability (BA) is very low ( $0.63 \%$ in a Caucasian population); and its absorption is reduced by the effects of food. It has a wide therapeutic window, and because it is not metabolized, the likelihood of drug interactions is low. Elimination from blood involves distribution of the drug to bone (40-50\%) and renal excretion; renal clearance (CLr) is about $60 \mathrm{~mL} / \mathrm{min}$. Renal clearance is directly proportional to creatinine clearance (CLcr). Redistribution from bone is slow, producing a multiphasic pattern for the time course of serum concentration. Urinary cross-linked C-telopeptide of Type I collagen ( $\mathrm{UCTX}$ ) is one of the bone absorption markers and produced by osteoclast-mediated bone resorption. uCTX is sensitive biomarker of PD response to ibandronate, an association between the serum concentration of ibandronate and UCTX is evident from investigations using a PK-PD model.

No clinical studies focusing on PK and PD in a Japanese population have been reported to date. In this study, we describe the PK and PD characteristics of ibandronate in a Japanese population after i.v. and oral administration. By comparing PK and PD data obtained with the oral route of administration with data obtained with the intravenous route of administration, we estimated the optimal dose of oral ibandronate in a Japanese population.

\section{Methods}

The results of three studies were evaluated in our assessment here: a Phase I study of oral ibandronate in healthy postmenopausal Japanese women; a Phase II study of oral ibandronate in Japanese patients with primary osteoporosis; and a Phase I study of i.v. ibandronate in postmenopausal Japanese women with osteopenia. All studies were performed in compliance with the Declaration of Helsinki, the Good Clinical Practice Guidelines of the International Conference on Harmonisation, and the respective study protocols. Approval was obtained from the institutional review boards established at each study site. The subjects were enrolled after receiving a full explanation of the study, freely giving their consent to participate in the study using the consent form, having met all of the inclusion criteria and none of the exclusion criteria, and after being judged suitable for participation in this study.

\subsection{Oral Phase I study}

The Phase I study was a single-center, double-blind, doseescalation, comparative study of single oral administration. The subjects were healthy postmenopausal women, and the main inclusion criteria were female sex, age 45-64 years, and at least 2 years postmenopausal at the time of informed consent (menopause was defined as the time of the last menstrual period). The main exclusion criteria were body mass index (BMI) of $<18$ or $>27 \mathrm{~kg} / \mathrm{m}^{2}$ and renal dysfunction that could potentially affect the PK of the drug. A total of 40 subjects were assigned to five groups of eight subjects each, each group receiving oral placebo, or 20,50, 100 , or $150 \mathrm{mg}$ oral ibandronate at fasting. PK observations involved measuring the serum concentrations of ibandronate immediately before administration, and at 10, 20, 30, and $40 \mathrm{~min}$, and at 1, 1.5, 2, 3, 4, 6, 8, 12, 14, 24, 32, and $48 \mathrm{~h}$ after administration, and measuring the urine concentration of ibandronate in samples obtained immediately before administration, and at $0-2,2-4,4-8,8-12,12-24$, 24-48, and 48-72 h after administration. PD observations involved measuring uCTX at $1 \mathrm{~h}$ before administration, and at $24,72,168,336$, and $672 \mathrm{~h}$ after administration. Safety was confirmed throughout the study period.

\subsection{Oral Phase II study}

The Phase II study was a multicenter, randomized, doubleblind, comparative study of multiple oral administration, in which subjects received the study drug once monthly for 4 months (total of four doses administrated). The subjects were Japanese patients with primary osteoporosis, and the main inclusion criteria were as follows: analytical value of bone mineral density (BMD) in the lumbar spine (L2-L4) of $<-2.5 \mathrm{SD}$ of the young adult mean $\left(0.714 \mathrm{~g} / \mathrm{cm}^{2}\right)$ as measured at screening by dual-energy X-ray absorptiometry (DXA) (Hologic QDR; Hologic, Bedford, MA, USA) at the study site; at least 5 years since natural menopause (menopause is defined as the time of the last menstrual period); and aged $>55$ years. The main exclusion criterion was any gastrointestinal disorder (e.g., subtotal gastrectomy) that could potentially affect PK. A total of 134 subjects (the safety analysis set) were assigned to five groups: subjects receiving oral placebo (28 subjects), or oral ibandronate $20 \mathrm{mg}$ (27 subjects), $50 \mathrm{mg}$ (27 subjects), $100 \mathrm{mg}$ (26 subjects), or $150 \mathrm{mg}$ (26 subjects). Ibandronate was administered at fasting. Six subjects from each ibandronate group (24 subjects in total) were evaluated for 
PK. PK observations involved measuring the serum and urine concentrations of ibandronate. Serum measurements were taken before the first dose of study drug (first day), at $30 \mathrm{~min}$ and 1, 2, 6, 12, 24, and $48 \mathrm{~h}$ after the first dose, before administration at 1 month (second dose), before administration at 2 months (third dose), before administration at 3 months (fourth dose), at 30 min and 1, 2, 6, 12, 24 , and $48 \mathrm{~h}$ after the fourth dose, and 1 month after the fourth dose (fourth month). The concentration of ibandronate in urine was measured in samples collected in the following periods: $-12 \mathrm{~h}$ until $0 \mathrm{~h}$ before first administration, and 0-6, 6-12, 12-24, and 24-48 h after first administration. PD observations involved measuring uCTX at prior to oral administration on the first and eighth days, after the 1,2, and 3 and 4 months, 3 months plus eighth days. Safety was assessed throughout the study period. A part of the efficacy and safety results of this study were reported by Nakamura et al. (2007).

\section{3 i.v. Phase I study (Pillai et al. 2006, 2004)}

The i.v. Phase I study was a placebo-controlled, singleblind study, in which subjects received the study drug twice, 13 weeks apart. The subjects were postmenopausal Japanese women ( $\geq 5$ years since menopause) with osteopenia, aged $60-75$ years, with obesity index of $\geq-20 \%$ and $\leq+20 \%$ (obesity index [\%] $=\{(100 \times$ weight $[\mathrm{kg}]) /$ (height $\left.\left.[\mathrm{m}]^{2} \times 22\right)\right\}-100$ ), lumbar BMD (L2-L4) as determined by DXA of greater than "mean -2.5 standard deviations (SD)" of the BMD in healthy, middle-aged women, and less than or equal to "mean -1.5 SD" (QDR2000 measurement; $0.83 \geq x>0.71 \mathrm{~g} / \mathrm{cm}^{2}$ ). The main exclusion criterion was renal disorder. A total of 50 subjects were assigned to five groups of ten subjects each, receiving the i.v. placebo, or i.v. ibandronate $0.25,0.5,1.0$, or $2.0 \mathrm{mg}$. PK observations involved measuring the serum concentrations of ibandronate at pre-dose, 5 , and $30 \mathrm{~min}$ and at 1,2, 4, 12, 24, 36, and $48 \mathrm{~h}$ after the first dose, and at pre-dose and $5 \mathrm{~min}$ and at $12,24,36$, and $48 \mathrm{~h}$ after the second dose, and the urine concentration of ibandronate was measured -12 to $0 \mathrm{~h}$ before, $0-12,12-24,24-48$, and 48-72 $\mathrm{h}$ after the first and second doses. Urine for measurement of UCTX was collected on the day of each administration and on days 4, 8, 15, 29, 57, and 92 after administration (after the second dose only). Safety was assessed throughout the study period.

2.4 Measurements of serum and urine concentrations of ibandronate (Endele et al. 2005) and uCTX

Serum concentrations of ibandronate were measured using solid-phase enzyme immunoassay, for which the quantifi- cation range was $50-800 \mathrm{pg} / \mathrm{mL}$. The urine concentration of ibandronate was measured using gas chromatographymass spectrometry, for which the quantification range was $2.5-2,000 \mathrm{ng} / \mathrm{mL}$. uCTX were measured using validated an enzyme linked immunosorbent assay.

\subsection{Data analysis}

WinNonlin (Pharsight, Mountain View, CA, USA) software was used for PK analyses. Tables and figures were prepared using S-PLUS software (Insightful, Seattle, WA, USA). In the comparison of exposure for oral and i.v. administration, the $\mathrm{AUC}_{\mathrm{inf}}$ data from the study of postmenopausal healthy women receiving $100 \mathrm{mg}$ oral ibandronate was combined with that for patients with primary osteoporosis receiving $100 \mathrm{mg}$ ibandronate oral and compared against the $\mathrm{AUC}_{\mathrm{inf}}$ data for postmenopausal patients with osteopenia receiving $1.0 \mathrm{mg}$ i.v. ibandronate.

\section{Results}

\subsection{Demographics and subject background}

Table 1 presents the characteristics of the Japanese women included in the PK analysis set for the oral Phase I study in healthy postmenopausal women, the oral Phase II study in patients with primary osteoporosis, and the i.v. Phase I study in postmenopausal women with osteopenia. Healthy postmenopausal women were youngest, followed in order by postmenopausal women with osteopenia and patients with postmenopausal osteoporosis. Body weights in the three groups were similar. Creatinine clearance was slightly lower in postmenopausal women with osteopenia receiving $0.25,0.5$, and $2 \mathrm{mg}$ i.v. ibandronate, but there were no major differences between the three groups.

\subsection{Pharmacokinetic data}

\subsubsection{Japanese healthy postmenopausal women}

Figure 1 and Table 2 show the time course of change in serum concentration of ibandronate in healthy postmenopausal Japanese women following a single oral dose of ibandronate. The time to maximum serum concentration $\left(T_{\max }\right)$ was $1-1.2 \mathrm{~h}$ (values shown here and below are mean values in each group), showing that absorption was rapid. The elimination half-life $\left(t_{1 / 2}\right)$ was similar across the groups receiving doses of $50-150 \mathrm{mg}$, ranging from 20 to $23 \mathrm{~h}$, and tended to be shorter in the $20 \mathrm{mg}$ group, at about $14 \mathrm{~h} . \mathrm{AUC}_{\mathrm{inf}}$ and $C_{\max }$ increased dose-dependently in the $20-100 \mathrm{mg}$ dose range, and at $150 \mathrm{mg}$ the 
Table 1 Characteristics of subjects in the pharmacokinetic analysis set

\begin{tabular}{|c|c|c|c|c|c|}
\hline Subjects & Groups & $\operatorname{Sex}(\mathrm{F} / \mathrm{M})$ & Age (years) & Weight (kg) & $\begin{array}{l}\text { Creatinine clearance } \\
(\mathrm{mL} / \mathrm{min})\end{array}$ \\
\hline \multirow[t]{4}{*}{ Postmenopausal healthy adults } & $20 \mathrm{mg}$ oral & $8 / 0$ & $60 \pm 2$ & $55 \pm 4$ & $110 \pm 21$ \\
\hline & $50 \mathrm{mg}$ oral & $8 / 0$ & $56 \pm 2$ & $53 \pm 5$ & $109 \pm 19$ \\
\hline & $100 \mathrm{mg}$ oral & $8 / 0$ & $57 \pm 5$ & $54 \pm 7$ & $100 \pm 20$ \\
\hline & $150 \mathrm{mg}$ oral & $8 / 0$ & $55 \pm 3$ & $55 \pm 8$ & $108 \pm 10$ \\
\hline \multirow[t]{4}{*}{ Primary osteoporosis } & $20 \mathrm{mg}$ oral & $6 / 0$ & $66 \pm 3$ & $48 \pm 6$ & $107 \pm 15$ \\
\hline & $50 \mathrm{mg}$ oral & $6 / 0$ & $66 \pm 4$ & $54 \pm 5$ & $103 \pm 18$ \\
\hline & $100 \mathrm{mg}$ oral & $6 / 0$ & $65 \pm 5$ & $51 \pm 6$ & $100 \pm 18$ \\
\hline & $150 \mathrm{mg}$ oral & $6 / 0$ & $64 \pm 5$ & $49 \pm 4$ & $105 \pm 29$ \\
\hline \multirow[t]{4}{*}{ Postmenopausal osteopenia } & $0.25 \mathrm{mg}$ i.v. & $10 / 0$ & $63 \pm 4$ & $54 \pm 7$ & $75 \pm 16$ \\
\hline & $0.5 \mathrm{mg}$ i.v. & $10 / 0$ & $65 \pm 4$ & $56 \pm 7$ & $77 \pm 12$ \\
\hline & $1.0 \mathrm{mg}$ i.v. & $10 / 0$ & $64 \pm 3$ & $57 \pm 7$ & $110 \pm 29$ \\
\hline & $2.0 \mathrm{mg}$ i.v. & $10 / 0$ & $64 \pm 4$ & $51 \pm 8$ & $74 \pm 10$ \\
\hline
\end{tabular}

Age, weight, and creatinine clearance values are mean \pm SD

Fig. 1 Serum concentration of ibandronate after an oral administration of ibandronate to healthy postmenopausal women (mean $\pm \mathrm{SD})$. The inset shows the relationship between dose and $\mathrm{AUC}_{\text {inf }}$ with linear regression curve

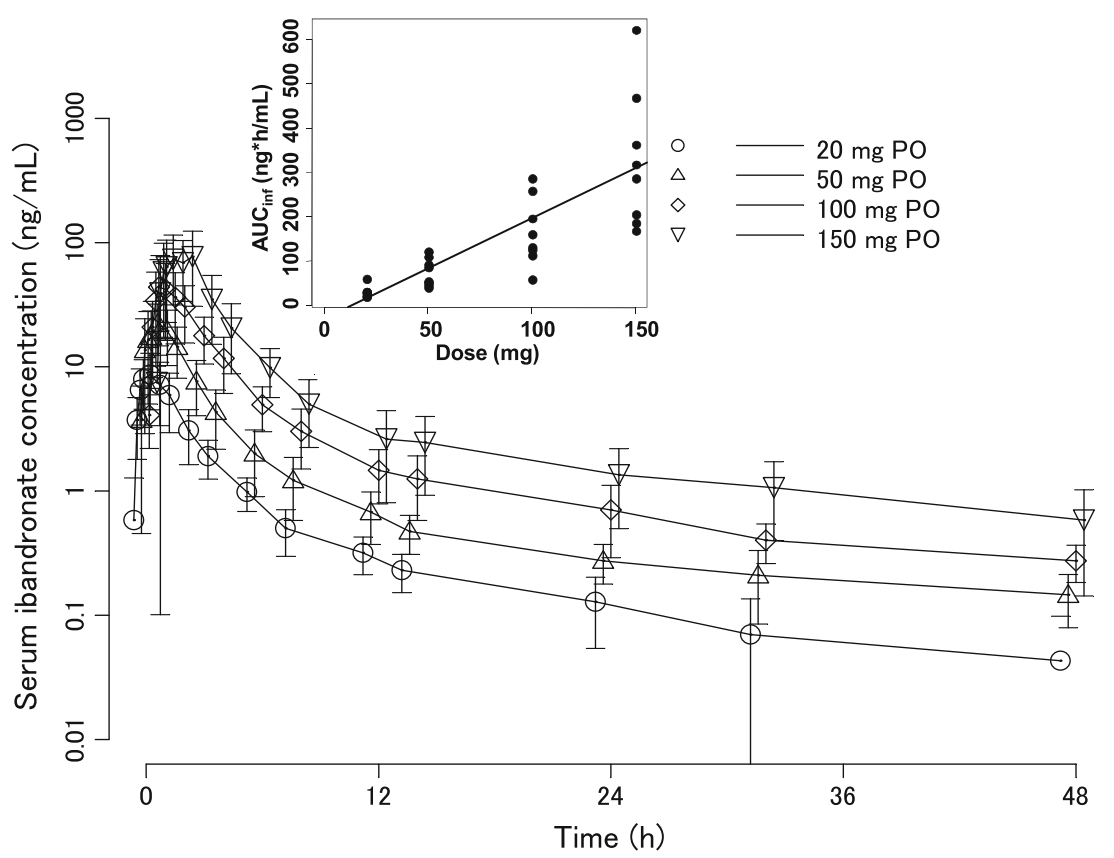

increase in these parameters was greater than the doseproportionality seen for doses up to $100 \mathrm{mg}$. Fraction of administered dose excreted in urine up to $72 \mathrm{~h}$ after administration was $0.542-1.08 \%$, of which $70-80 \%$ was excreted in the first $8 \mathrm{~h}$. The cumulative urinary excretion thereafter increased increasingly gradually, and excretion of ibandronate to urine was almost complete by $72 \mathrm{~h}$ after administration.

\subsubsection{Japanese patients with primary osteoporosis}

Table 2 shows PK parameters in Japanese patients with primary osteoporosis given four doses of monthly oral ibandronate. The serum concentration of ibandronate increased dose-dependently (Fig. S1 A), rapidly reached a maximum between 0.75 and $1.07 \mathrm{~h}$ after administration, then decreased to $<5 \%$ of the maximum value by $12 \mathrm{~h}$ after administration. Similar profiles were observed after the first and fourth doses. In the 20-100 mg dose range, $\mathrm{AUC}_{\mathrm{inf}}$ and $C_{\max }$ increased dose-proportionally, and at $150 \mathrm{mg}$ these parameters increased at rates greater than the dose-proportionality seen at doses up to $100 \mathrm{mg}$. Fraction of administered dose excreted in urine up to $48 \mathrm{~h}$ after administration was $0.407-1.08 \%$, about $80 \%$ of which was excreted in the first $6 \mathrm{~h}$. The cumulative urinary excretion thereafter increased increasingly gradually, and excretion of ibandronate to urine was almost complete by $48 \mathrm{~h}$ after administration. 


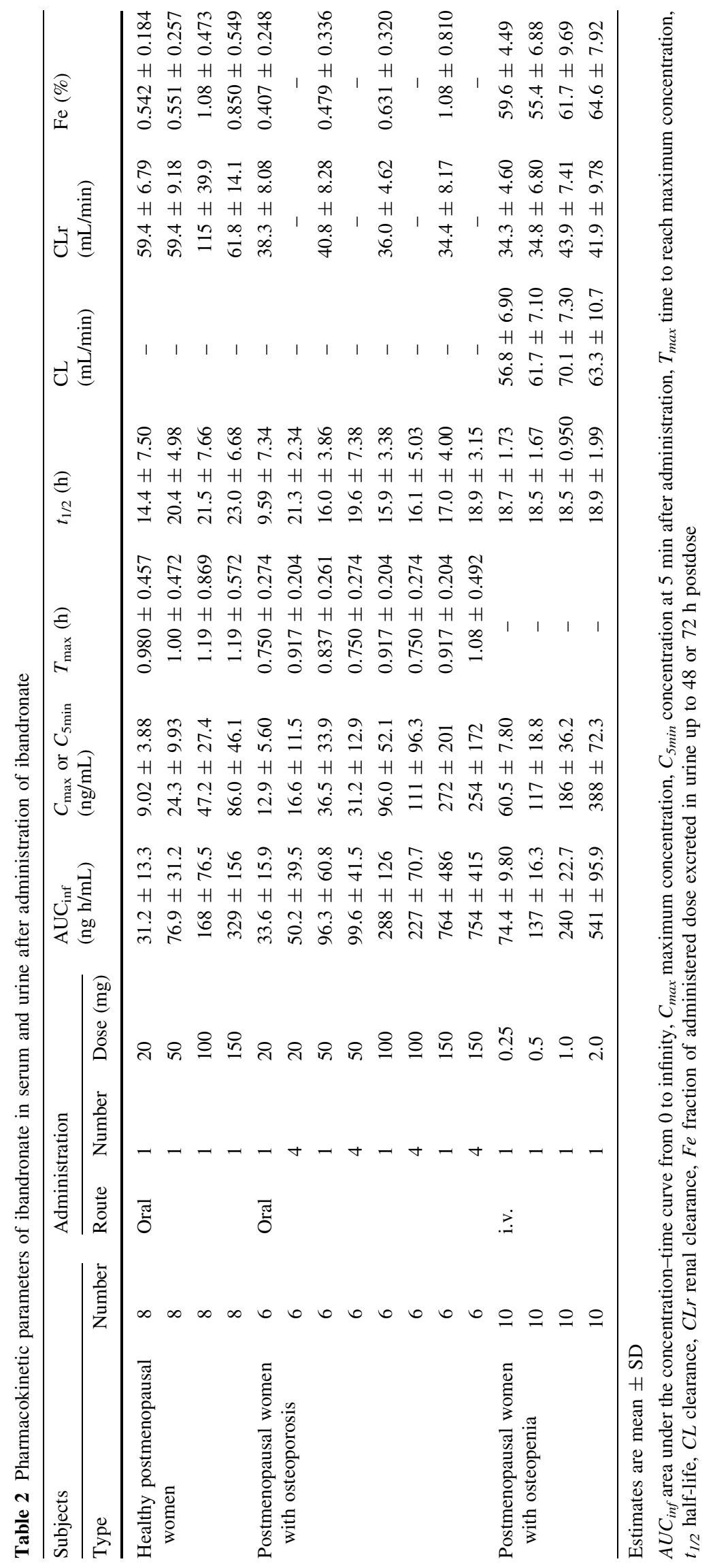


Table $3 \mathrm{AUC}_{\mathrm{inf}}$ for ibandronate in serum after oral and intravenous administration of ibandronate

\begin{tabular}{lllll}
\hline Population & Dose/route & $\begin{array}{l}\text { Body weight } \\
(\mathrm{kg})\end{array}$ & $\begin{array}{l}\text { Creatinine clearance } \\
(\mathrm{mL} / \mathrm{min})\end{array}$ & $\begin{array}{l}\text { AUC } \\
(\mathrm{ng} \mathrm{h} / \mathrm{mL})\end{array}$ \\
\hline $\begin{array}{l}\text { Postmenopausal healthy women + postmenopausal } \\
\text { women with osteoporosis }\end{array}$ & $100 \mathrm{mg} / \mathrm{oral}$ & $53 \pm 7(n=14)$ & $94 \pm 20(n=14)$ & $219 \pm 114(n=14)$ \\
\begin{tabular}{l} 
Postmenopausal women with osteopenia \\
\hline
\end{tabular} & $1.0 \mathrm{mg} /$ i.v. & $57 \pm 7(n=10)$ & $110 \pm 29(n=10)$ & $240 \pm 22.7(n=10)$ \\
\hline
\end{tabular}

Values are mean $\pm \mathrm{SD}$

\subsubsection{Japanese postmenopausal women with osteopenia}

Table 2 shows PK parameters in postmenopausal Japanese women with osteopenia given i.v. ibandronate. The serum concentration profiles of ibandronate after the first administration (first dose) and second administration were similar (Fig. S1 B). After administration of ibandronate in the 0.25-2 $\mathrm{mg}$ dose range, $\mathrm{AUC}_{\mathrm{inf}}$ and the serum concentration at 5 min postdose $\left(C_{5 \mathrm{~min}}\right)$ increased in a dose-dependent manner. Similar $t_{1 / 2}$ values were observed in all dose groups (18.5-18.9 h). By $72 \mathrm{~h}$ postdose, 55.4-64.6\% of the administered ibandronate had been excreted in urine.

\subsubsection{Comparison of exposures in oral and i.v. administration}

$\mathrm{AUC}_{\text {inf }}$ after administration of $100 \mathrm{mg}$ oral ibandronate within the linear range of $\mathrm{PK}$ was $219 \pm 114 \mathrm{ng} \mathrm{h} / \mathrm{mL}$; this value was calculated by pooling the data from the healthy postmenopausal women and the women with primary oste-

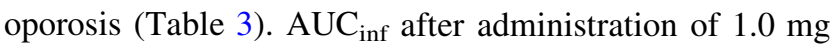
i.v. ibandronate, which is the i.v. dose of ibandronate approved for use in postmenopausal women with osteopenia, was $240 \pm 23 \mathrm{ng} \mathrm{h} / \mathrm{mL}$. These results show that ibandronate exposure after administration of $100 \mathrm{mg}$ oral ibandronate was similar to that after administration of $1.0 \mathrm{mg}$ i.v. ibandronate. $\mathrm{AUC}_{0-48 \mathrm{~h}}$ after administration of $100 \mathrm{mg}$ oral ibandronate was $209 \pm 111 \mathrm{ng} \mathrm{h} / \mathrm{mL}$ by pooling the data from the healthy postmenopausal women and the women with primary osteoporosis. $\mathrm{AUC}_{0-48 \mathrm{~h}}$ after administration of $1.0 \mathrm{mg}$ i.v. ibandronate was $230 \pm 20.8 \mathrm{ng} \mathrm{h} / \mathrm{mL}$. These results show the similarity of $\mathrm{AUC}_{0-48 \mathrm{~h}}$ and $\mathrm{AUC}_{\mathrm{inf}}$.

\subsection{Pharmacodynamic data}

\subsubsection{Japanese healthy postmenopausal women}

Creatinine-corrected uCTX levels decreased dose-dependently in the ibandronate groups (Fig. 2). In the $20 \mathrm{mg}$ group, the suppression magnitude was negligible compared with that in the placebo group. However, clearly greater suppression was observed in the 50, 100, and $150 \mathrm{mg}$ groups. uCTX levels decreased immediately and reached a minimum at 3-7 days after administration. uCTX levels subsequently slowly increased, but the levels in these three dose groups remained lower than in the placebo group for up to 28 days after administration.

\subsubsection{Japanese patients with primary osteoporosis}

The uCTX levels in the ibandronate-treated groups decreased dose-dependently (Fig. S2 A). The suppression in the $20 \mathrm{mg}$ group was only negligible compared with that in the placebo group, but greater suppression was observed in the 50, 100, and $150 \mathrm{mg}$ groups. uCTX levels decreased from immediately after administration, with the minimum measurement observed at Day 8. The levels subsequently gradually increased, but remained lower in the groups receiving $50-150 \mathrm{mg}$ than in the placebo group, even at 1 month after administration.

\subsubsection{Japanese postmenopausal women with osteopenia}

The uCTX levels decreased rapidly up to 8 days after administration of ibandronate and increased gradually thereafter (Fig. S2 B). The suppression in the groups receiving doses of $0.5-2 \mathrm{mg}$ were dose-dependent, but the decrease in the $0.25 \mathrm{mg}$ group was almost the same as that in the placebo group. The time course of change in uCTX levels after the second dose was similar to that after the first dose.

\section{Discussion}

The PK and PD profiles of ibandronate delivered by oral and i.v. routes were compared by using the data of serum concentration, AUC, and uCTX levels from three Japanese studies. Oral ibandronate was rapidly absorbed, reaching $C_{\max }$ at $0.75-1.19 \mathrm{~h}$ after oral administration. After administration of $20,50,100$, or $150 \mathrm{mg}$ oral ibandronate to healthy postmenopausal women and patients with primary osteoporosis, $\mathrm{AUC}_{\mathrm{inf}}$ increased dose-proportionally at doses up to $100 \mathrm{mg}$, but the increase at $150 \mathrm{mg}$ was greater than the dose-proportionality seen with the lower doses. The $\mathrm{AUC}_{\mathrm{inf}}$ values following administration of $100 \mathrm{mg}$ oral ibandronate were similar to those following $1.0 \mathrm{mg}$ i.v. ibandronate. The 
Fig. 2 Creatinine-corrected urinary CTX values (mean $\pm \mathrm{SD}$ ) after an oral administration of ibandronate to healthy postmenopausal women
Fig. 3 Percentage changes (mean $\pm \mathrm{SD}$ ) from baseline in creatinine-corrected urinary CTX after administration of $100 \mathrm{mg}$ oral ibandronate and $1.0 \mathrm{mg}$ i.v. ibandronate
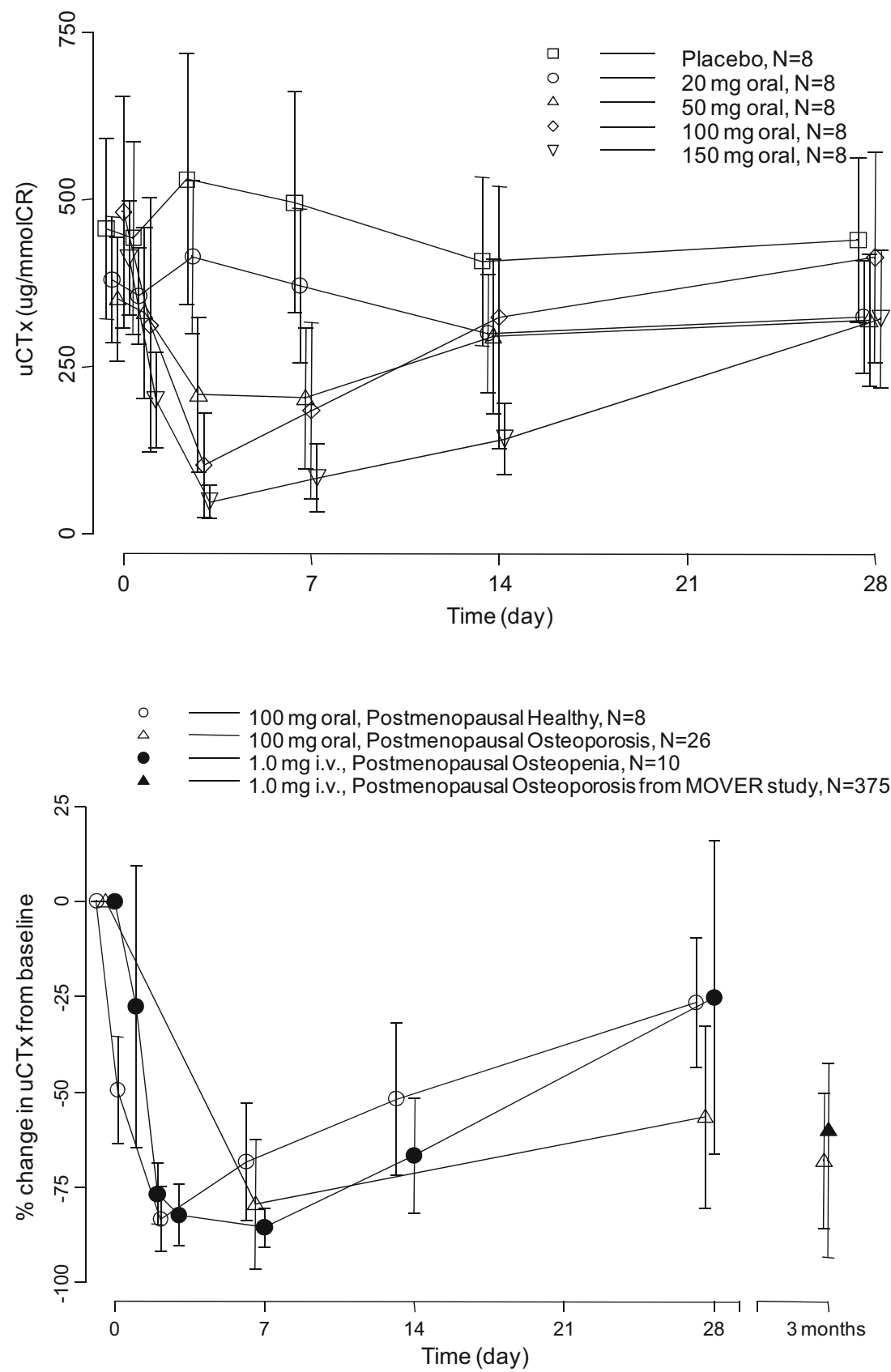

decrease in uCTX levels after $100 \mathrm{mg}$ oral ibandronate persisted for 1 month (Fig. 3). At 1 month, the decrease in uCTX levels after $100 \mathrm{mg}$ oral ibandronate in patients with primary osteoporosis was greater than the decrease in uCTX levels in healthy postmenopausal women given $100 \mathrm{mg}$ oral ibandronate or in postmenopausal women with osteopenia given $1.0 \mathrm{mg}$ i.v. ibandronate. In the MOVER study (Nakamura et al. 2013), the suppression of uCTX levels at 3 months was $-60.0 \%$, similar to that at 3 months in patients with primary osteoporosis who received $100 \mathrm{mg}$ oral ibandronate $(-70.0 \%)$. In Japanese patients, the PK and PD characteristics of $100 \mathrm{mg}$ monthly oral ibandronate were similar to those of $1.0 \mathrm{mg}$ monthly i.v. ibandronate.

Lin (1996) reported that in the preclinical study of alendronate, which is of the same pharmacological class (bisphosphonate) as ibandronate, oral bioavailabilities at doses of 2 and $40 \mathrm{mg} / \mathrm{kg}$ were 0.5 and $5 \%$, respectively. He suggested that the reason why the bioavailability changed depending on the dose was due to the heightened absorption via the paracellular pathway, which is the main route of absorption of alendronate from the gastrointestinal tract (Lin 1996). In brief, alendronate captures calcium ions which form tight junction with specific proteins in the 
gastrointestinal tract, thereby widening the intercellular spaces and facilitating the greater influx of alendronate from the gastrointestinal tract (Lin 1996). We consider that a possible reason for the nonlinearity of exposure to ibandronate at $150 \mathrm{mg}$ is that its bioavailability might be increased via a mechanism similar to that of alendronate. $\mathrm{AUC}_{\text {inf }}$ of $150 \mathrm{mg}$ oral ibandronate increased beyond the dose-proportionality seen at doses of 20-100 $\mathrm{mg}$, and drug-related adverse events occurred at a higher rate $(69.2 \%)$ at $150 \mathrm{mg}$ than at doses of $20-100 \mathrm{mg}$ (22.2-34.6\%) (Nakamura et al. 2007).

Ibandronate was mainly eliminated via urinary excretion as unchanged drug after i.v. administration (Table 2). Extra-renal elimination pathway of ibandronate was suggested by Barrett et al. (2004). No metabolites of ibandronate were detected in plasma after administration to human and rat. Following absorption and initial systemic exposure, ibandronate was distributed and bound to bone (40-50\% of systemic exposure), then it was released from the bone over a period of years and renally excreted.

Pillai et al. (2006) reported in a population pharmacokinetics study of ibandronate that disease status, body weight, sex, and creatinine clearance might affect the PK of ibandronate. They stated that ibandronate exposure increased when the disease status of osteoporosis was advanced, body weight was low, the sex was female, or creatinine clearance was low (Pillai et al. 2006). In our research, there was a tendency for the exposure to be higher in patients with primary osteoporosis than in healthy postmenopausal women. The body weights of these healthy postmenopausal women ranged from 52.8 to $55.0 \mathrm{~kg}$ and those of patients with primary osteoporosis ranged from 47.9 to $53.8 \mathrm{~kg}$. The difference in $\mathrm{AUC}_{\mathrm{inf}}$ observed between healthy postmenopausal women and patients with primary osteoporosis may have been caused by the differences in disease status and weight.

The approved dose of i.v. ibandronate in Japan is $1.0 \mathrm{mg} /$ month; this is based on the clinical evidence of the MOVER study (Nakamura et al. 2013). In order to compare $\mathrm{AUC}_{\mathrm{inf}}$ between the two routes of administration, it is necessary that the subject characteristics that can affect the PK of ibandronate be consistent between the groups receiving the different dosage forms. By pooling the data for healthy postmenopausal women and the patients with primary osteoporosis who received $100 \mathrm{mg}$ oral ibandronate, the body weight and creatinine clearance values were similar to those in postmenopausal women with osteopenia who received $1.0 \mathrm{mg}$ i.v. ibandronate, showing that the subject characteristics were comparable. Furthermore, the disease status of osteoporosis progresses in ascending order from healthy adults, through patients with osteopenia, to patients with osteoporosis. Hence, when healthy postmenopausal women and patients with primary osteoporosis who received $100 \mathrm{mg}$ oral ibandronate were combined, the subject characteristics that affect PK were comparable to those of postmenopausal women with osteopenia who received $1.0 \mathrm{mg}$ i.v. ibandronate. The bioavailability of oral ibandronate, calculated from the $\mathrm{AUC}_{\mathrm{inf}}$ values following oral and i.v. administration, was $0.913 \%$. Annual cumulative exposure (ACE) of $1.0 \mathrm{mg}$ i.v. ibandronate was estimated to be $12 \mathrm{mg}(1.0 \mathrm{mg} \times 12$ times $\times 100 \%)$, and a similar ACE would be obtained with oral ibandronate $(11.0 \mathrm{mg} ; 100 \mathrm{mg} \times 12$ times $\times 0.913 \%)$.

The optimal oral dose of ibandronate was suggested to be $100 \mathrm{mg}$ in Japanese population, on the other hand, it was $150 \mathrm{mg}$ in Western population. This difference might be derived from the difference of bioavailability between these Japanese and Western population (0.91 versus $0.63 \%$ ), however, the mechanism of this difference of bioavailability is unclear. Risedronate is the same pharmacological class drug as ibandronate. The optimal oral dose of risedronate in Japanese population is higher than Western population $(2.5$ versus $5.0 \mathrm{mg}$ ) because of the difference of the bioavailability, although the reasons for this difference remain unknown (Ogura et al. 2004).

The inhibitory effect of ibandronate on uCTX is associated with the increasing effect of ibandronate on BMD, and it has been reported that UCTX is a useful predictive marker for the treatment of osteoporosis with ibandronate (Pillai et al. 2004; Reginster and Gieschke 2006; Gieschke et al. 2003). Here we showed the time course of change in uCTX levels as the PD profile of ibandronate.

In terms of PK, exposure (AUC of ibandronate) after administration of $100 \mathrm{mg}$ oral ibandronate is similar to that after $1.0 \mathrm{mg}$ i.v. ibandronate. Based on the results of this comparison, the optimal dose for oral administration of ibandronate in Japanese osteoporotic patients is anticipated to be $100 \mathrm{mg} / \mathrm{month}$. From the perspective of suppression of uCTX, a $100 \mathrm{mg}$ oral dose is deemed appropriate because the suppression of uCTX by $100 \mathrm{mg}$ oral ibandronate was similar to that by $1.0 \mathrm{mg}$ i.v. ibandronate.

Acknowledgments The authors thank Dr. Ronald Gieschke and Dr. Bruno Reigner, F. Hoffmann-La Roche Ltd., for discussing the study results with them.

Open Access This article is distributed under the terms of the Creative Commons Attribution Noncommercial License which permits any noncommercial use, distribution, and reproduction in any medium, provided the original author(s) and the source are credited.

\section{References}

Barrett J, Worth E, Bauss F, Epstein S (2004) Ibandronate: a clinical pharmacological and pharmacokinetic update. J Clin Pharmacol 44:951-965

Dunford JE, Thompson K, Coxon FP, Luckman SP, Hahn FM, Poulter CD, Ebetino FH, Rogers MJ (2001) Structure-activity 
relationships for inhibition of farnesyl diphosphate synthase in vitro and inhibition of bone resorption in vivo by nitrogencontaining bisphosphonates. J Pharmacol Exp Ther 296:235-242

Endele R, Loew H, Bauss F (2005) Analytical methods for the quantification of ibandronate in body fluids and bone. J Pharm Biomed Anal 39:246-256

Gieschke R, Hayashi N, Vis P, Jacqmin P (2003) Modelling the effects of ibandronate treatment on the time course of bone mineral density in osteoporotic postmenopausal women. In: 30th European Symposium on Calcified Tissues (ESCT), Rome, Italy

Lin JH (1996) Bisphosphonates: a review of their pharmacokinetic properties. Bone 18:75-85

Nakamura T, Mizunuma H, Itabashi A, Yamane H, Hannita T, Karube M, Takeuchi K, Ikegami R, Okamoto S, Hasunuma T, Kumagai Y (2007) Monthly oral ibandronate is well tolerated and efficacious in Japanese osteoporotic subjects. J Bone Miner Res 22(Suppl 1):S333

Nakamura T, Nakano T, Ito M, Hagino H, Hashimoto J, Tobinai M, Mizunuma H, MOVER Study Group (2013) Clinical efficacy on fracture risk and safety of $0.5 \mathrm{mg}$ or $1 \mathrm{mg} / \mathrm{month}$ intravenous ibandronate versus $2.5 \mathrm{mg} /$ day oral risedronate in patients with primary osteoporosis. Calcif Tissue Int 93:137-146

Ogura Y, Gonsho A, Cyong JC, Orimo H (2004) Clinical trial of risedronate in Japanese volunteers: single and multiple oral dose studies. J Bone Miner Metab 22:111-119

Pillai G, Gieschke R, Goggin T, Jacqmin P, Schimmer RC, Steimer JL (2004) A semimechanistic and mechanistic population PKPD model for biomarker response to ibandronate, a new bisphosphonate for the treatment of osteoporosis. Br J Clin Pharmacol 58:618-631

Pillai G, Gieschke R, Goggin T, Barrett J, Worth E, Steimer JL (2006) Population pharmacokinetics of ibandronate in Caucasian and Japanese healthy males and postmenopausal females. Int J Clin Pharmacol Ther 44:655-667

Reginster JY, Gieschke R (2006) Clinical utility of a pharmacostatistical model for ibandronate in postmenopausal osteoporosis. Curr Drug Metab 7:827-836 